\title{
Education research in emergency medicine
}

\author{
Lawrence E. Kass ${ }^{1}$
}

Received: 8 March 2016/Accepted: 14 March 2016/Published online: 13 April 2016

(C) SIMI 2016

Articles in the medical literature on the pedagogy of medical education are a relatively new phenomenon. While we have been interested in what to teach, few academic physicians have spent time studying how to teach, or assess the effectiveness of that teaching. But emergency medicine, along with other specialties, has seen a dramatic and sustained increase in the number of studies on education in medicine over the last decade [1]. This month's issue of Internal and Emergency Medicine contains three articles addressing topics in education.

Hoyer et al. [2] described a technique for using fresh perfused cadavers to teach medical students how to use ultrasound to assist central vascular access and pericardiocentesis. Though this was not a controlled study, and the results are potentially limited by the relatively small size of the population studied, surveys of the students found a dramatic increase in both knowledge about the use of ultrasound and confidence in performing the procedures. The next step would be to compare this cadaver technique to commercially available mannequins in terms of cost, time, and, most importantly, the outcome of learner skill.

Nocera et al. [3] report on their experience of creating a formal resident research program that includes milestones for each of the 3 years of training, departmental resources to support the research, and clear expectations for presenting the projects (at least internally within their department if not at a scientific conference). In 3 years since the inception of their "Think, Do, Write" program, they have found a dramatic increase in both the number of

Lawrence E. Kass

lkass@hmc.psu.edu

1 Penn State Milton S Hershey Medical Center, Hershey, PA, USA empirical projects and the number of resident presentations at academic meetings. While the Hawthorne effect may have played a role in the upsurge in resident research, if their results are sustainable over time they will have demonstrated that spending the time and money necessary to create this program is effective in improving the quantity and quality of resident research.

Williamson et al. [4] fill an important gap in the ACGME outcomes-based milestones by providing a list of suggested remediation techniques for each of the subcompetencies under the six domains. Their lists of suggestions are based on personal experience supplemented by consultation with other education leaders and review of the relevant literature. As such, this novel guide provides a single source for a wide variety of ideas and techniques for remediating the "problem resident."

In sum, these three articles nicely frame the brave new world of medical education. The apprenticeship model that describes much of how students became doctors in the twentieth century worked well, but had many flaws. The "see one, do one, teach one" style of teaching procedures was ineffective for uncommon procedures, and could put patients at risk by exposing them to ill-prepared providers. Simulation, including the use of cadavers as described here, has been an important step in changing that. Resident research has always been deemed important, and those of us fortunate enough to find a strong mentor benefited tremendously from that experience. Nevertheless, to ensure that all residents get that opportunity requires a systematic, department-wide approach. The "Think, Do, Write" program described here is an excellent example of such an approach. We are increasingly aware that we live in a global community and share common challenges that are often amenable to common solutions. Resources such as the "problem resident behavior guide" allow us, as 
educators, to share our experience and knowledge with each other. It is up to us, the products of twentieth century training, to continue to develop and incorporate these new pedagogies as we teach the physicians of the twenty first century.

\section{Compliance with ethical standards}

Conflict of interest The author declares that he has no conflict of interest.

Statement of human and animal rights This article does not contain any studies with human participants or animals performed by any of the authors.

Informed consent Informed consent was not required for this retrospective study.

\section{References}

1. Fisher J, Lin M, Coates WC, Kuhn GJ et al (2013) Critical appraisal of emergency medicine educational research: the best publications of 2011. Acad Emerg Med 20:200-208

2. Hoyer R, Means R, Robertson J, Rappaport D, Schmier C, Jones T, Stolz LA, Kaplan SJ, Adamas-Rappaport WJ, Amini R (2015) Ultrasound-guided procedures in medical education: a fresh look at cadavers. Intern Emerg Med. doi:10.1007/s11739-015-1292-7

3. Nocera R, Ramoska EA, Hamilton RJ (2016) Building a resident research program in emergency medicine. Intern Emerg Med. 11(2):245-248. doi:10.1007/s11739-015-1354-x

4. Williamson K, Quattromani E, Aldeen A (2015) The problem resident behavior guide: strategies for remediation. Intern Emerg Med. doi:10.1007/s11739-015-1367-5 